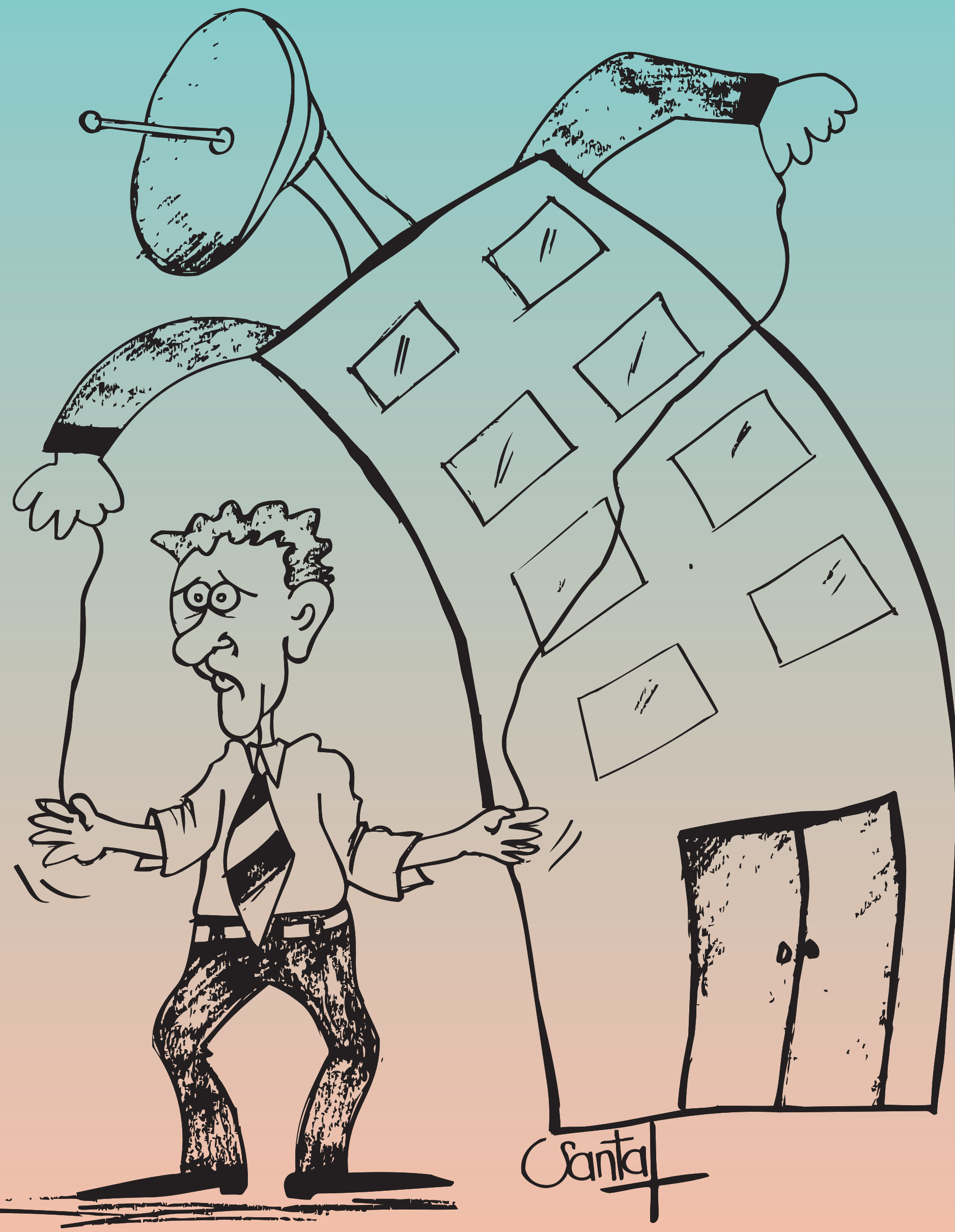




\section{Las fuentes de}

\section{información retratan \\ la realidad de un país}

Marcel Merizalde Guerra*

Fecha entrega: 2013-04-21 • Fecha aprobación: 2013-05-02

\section{Resumen}

En este artículo, se presenta una visión hermenéutico-crítica del uso y alcance sociocultural de las fuentes de información periodística. A lo largo de nueve subtemas, se muestra qué es una fuente de información, los tipos de esta y se explica para qué sirve.

También se analiza su alcance en la sociedad contemporánea, su relación con el poder y el valor significativo que guardan las fuentes de información periodística para retratar de cuerpo entero a un país.

Además, se explica cómo, al prescindir de su uso o hacerlo de forma imprecisa, se genera un ejercicio cuasi delictivo de la profesión periodística, esto en el caso particular del periodismo ecuatoriano.

Para finalizar, el lector encontrará un brevísimo estudio sobre quiénes son las fuentes de información periodística en el Ecuador, el mismo que revela no una novedad, sino un secreto a voces y de larga data.

\section{Palabras clave}

Periodismo, fuentes de información técnica, estilo, cultura, sociedad, política, novedad, realidad, verdad, verosimilitud, significados, argumentos, apropiación.

* W. Marcel Merizalde Guerra, 41 años de edad, nacido en Quito - Ecuador. Es licenciado en Comunicación Social por la Universidad Central del Ecuador, con especialidad en Investigación. También es especialista en Investigación Social e Ingeniería de Medios Impresos. Además, es máster en Género, Equidad y Desarrollo, con especialidad en Ambiente. Periodista y diseñador gráfico. Prestó servicios para medios de comunicación social dentro y fuera del país. Consultor y consejero en comunicación y política para organismos nacionales e internacionales. Es coautor del libro Periodismo Creativo - El Método Cort, autor de Periodismo de Investigación, Comunicometría y de un estudio sobre el comportamiento de los medios impresos ecuatorianos en la relación al gobierno del presidente Lucio Gutiérrez con el movimiento indígena. Actualmente, es profesor titular de la Facultad de Comunicación Social, de la Universidad Central del Ecuador, en las cátedras de Periodismo y Comunicación en Impresos. 
Abstract

In this report, we present a vision-critical hermeneutical use and sociocultural scope of journalistic information sources. Along nine sub displays show which is a source of information, types of this and explains what it does.

It also discusses its scope in contemporary society, its relationship with the power and the significant value that keep the sources in journalism to portray full-length to a country.

It also explains how to use or dispense it imprecisely, it generates a quasi-criminal exercise of journalism, that in the particular case of Ecuadorian journalism.

To end the reader will find a brief survey about who are the sources in journalism in Ecuador, the same one that reveals not a novelty, but an open secret and long-standing

\section{Palabras clave}

Periodism, sources of tecnichal information, style, culture, society, polítical, novelty, reality, true, plausibility, meanings, arguments, appropiation
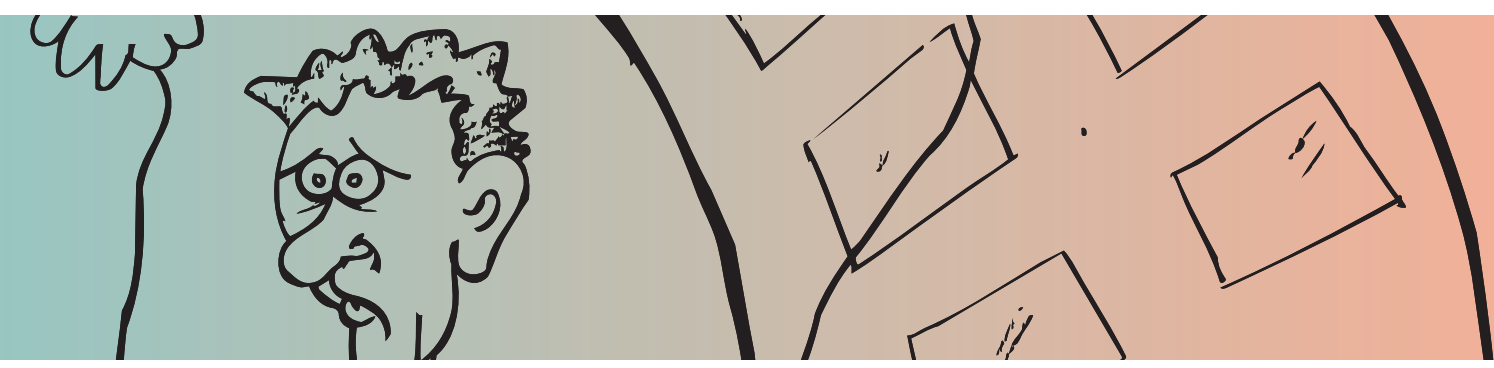

\section{A modo de introducción}

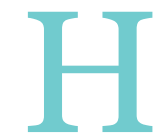

ablar de fuentes de información, en la sociedad contemporánea, parecería un ejercicio cargado de trivialidad. Esto, porque hoy todos los seres humanos hacen uso de estas, de forma automática, sin pensar en su significado y alcance sociocultural.

Una conversación de pasillo está llena de fuentes de información, casi siempre implícitas, lo que la convierte en una práctica básica y sensual de la interrelación humana. Los profesionales, de distintas áreas del conocimiento, las usan para construir argumento sobre algo que consideran relevante. Y, los periodistas, quienes son los más activos constructores del decir cotidiano, utilizan fuentes de información para relatar asuntos de importancia, a nivel masivo.

Pregunta obvia: ¿qué hace tan apetecible a una fuente de información en la sociedad contemporánea? La respuesta es sencilla, pero de una complejidad casi absoluta: la fuente de información, periodística, en el caso de este artículo, es una especie de validador de las novedades socioculturales. 
La cuestión, es que el mundo globalizado produce novedades de forma sostenida y progresiva. Sin embargo, una novedad no puede existir por su cuenta, sino que necesita de una base que le otorgue verosimilitud, credibilidad y algún grado de 'certeza'.

Entonces, la novedad no existe sin una fuente de información. Una fuente es parte de la técnica y estilo profesional, pero desborda estos límites y se traslada al epicentro político de la producción de sentidos y argumentos en una sociedad. Ahí radica su importancia y fortaleza.

\section{Fuentes de información perio- dística}

Para definir lo que es una fuente de información, es preciso utilizar los presupuestos del maestro latinoamericano del periodismo, José Antonio Benítez, quien sostiene que son las personas, documentos, grabaciones de audio y vídeo, objetos y organismos de la naturaleza, que pueden proporcionar información útil, sobre un hecho novedoso, en un momento determinado, a quienes ejercen el periodismo (Benítez, 1971: 41).

Por decirlo de otra manera, una fuente de información es parte de esa materia prima, junto al hecho novedoso, objeto del relato periodístico, que el operador semántico o periodista utiliza de forma rigurosa, o al menos debería hacerlo de esa manera, para construir noticia o novedad de interés sociocultural.

Una fuente de información es el ser humano y su palabra, quizá la más clásica y conocida, pero también los objetos que utiliza en su vida cotidiana y los significados que asigna a estos. Por lo tanto, una fuente de información conlleva una particular cosmovisión y un ejercicio ide- ológico concreto, histórico y dinámico. Estas cargas, cosmovisión e ideología, son asignadas, inclusive de forma no consciente y menos aún planificada, por sus usuarios.

A esta definición, se puede añadir que también son fuentes de información todos los objetos de la cultura, que proporcionan, en algún momento, información de interés colectivo para ser publicada o compartida a través de los medios de comunicación social. Por objetos de la cultura, entiéndase todos los bienes, reales y simbólicos, elaborados por el ser humano en su recorrido histórico.

\section{Los múltiples significados de una fuente}

Pensar las fuentes de información, en el periodismo y entre los periodistas, tambien parecería un ejercicio innecesario e incómodo, pues supone parte de la práctica profesional, técnica y rigurosa, de quienes ejercen esta actividad.

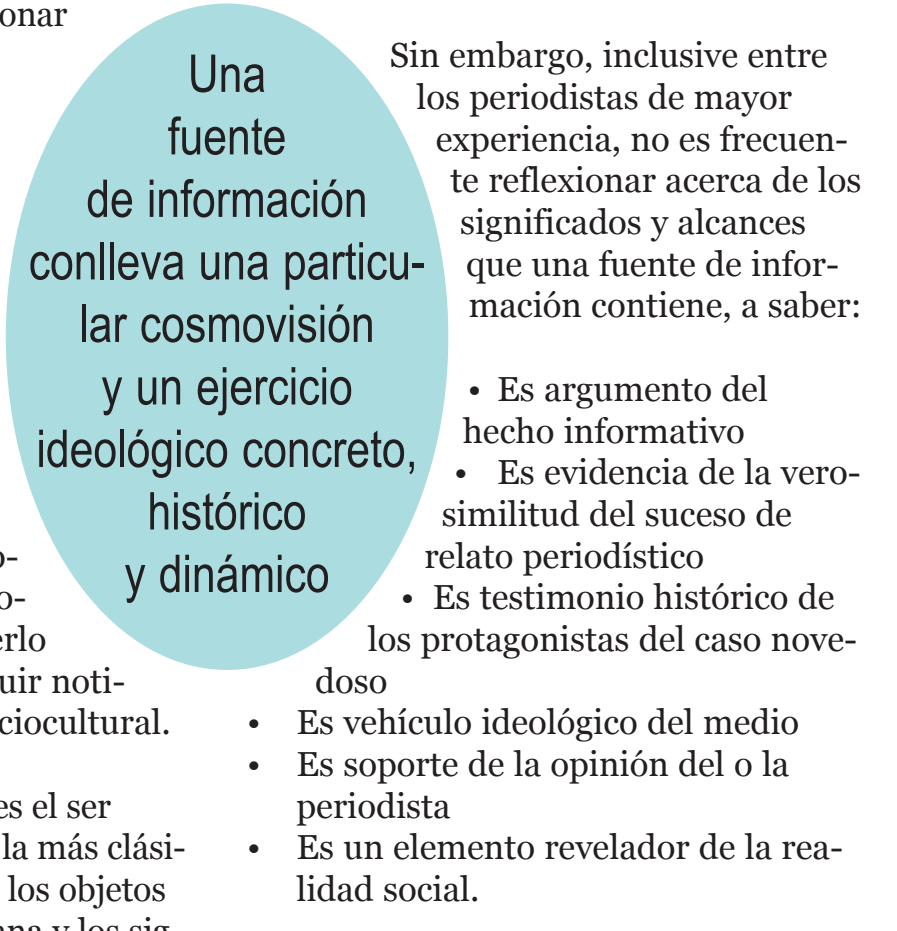

De estas afirmaciones, puede deducirse que una fuente de información, además de ser un elemento fundante del relato, 
de la técnica y estilo periodísticos, es una herramienta que utiliza el poder, que está detrás y al frente de los medios de comunicación, para difundir ideas, conceptos y significados que le son propicios en un momento histórico determinado.

Y, aunque no sea la manipulación el fin consciente de quien utiliza una fuente, en calidad de periodista, esta vehiculiza las intencionalidades de los verdaderos productores mediáticos y socioculturales de significados, a la vez que genera sentidos que facilitan una apropiación de la realidad, en términos lingüísticos y políticos, particularmente.

Arnaud Saint-Paul, en la primera edición 2013 de la Revista Electrónica de Ciencia, Tecnología y Sociedad, recuerda que: "Desde tiempos inmemoriales, tener la información justa en el momento oportuno ha significado 'poder' y solamente las personas o grupos de personas (nobles, iglesia, guildas y más adelante, empresarios, gobiernos) que se podían permitir financiar ese intercambio de información disfrutaron de ese privilegio." (Saint-Paul, 2013: http/www.estrategia21.net. Acceso, 8 de enero de 2013).

Una fuente de información, entonces, se proyecta en el escenario informativo y sociocultural como un arma compleja, que permite a quienes la poseen, conquistar la realidad y hacerse con los bienes simbólicos de los vencidos, en esa permanente batalla de significados que protagonizan los seres humanos en su vida cotidiana y el devenir político.

Pero, para entender también el poder que tiene una fuente de información, hay que comprender la crisis del paradigma periodístico, respecto de la comunicación, que se proyecta ahora como una anomalía, en el sentido que a este término le da Tomas Kuhn.

De acuerdo con palabras de este filósofo, los paradigma son "realizaciones universalmente reconocidas que, durante cierto tiempo, proporcionan modelos de problemas y soluciones a una comunidad científica"(Kuhn, 1971: 77). Y el periodismo, ciertamente, desbordó ya los límites de tránsito y significado que le aportaba la comunicación.

El periodismo, por acordar con referencias y sugerencias de pensadores de esta disciplina, como el cubano José Antonio Benítez y el español Enrique De Aguinaga, ya no se desarrolla a la sombra de otras disciplinas (De Aguinaga, 2008; Benítez, 2001) y menos es una versión inacabada, incompleta o menor de estas.

De hecho, puede decirse que el periodismo define una gramática particular, que es exploración y explicación de la realidad, más técnica y estilo, para el objeto de su trabajo, que es el relato sociocultural masivo.

\section{Tipos de fuentes de información}

Existen clasificaciones amplias y diversas, ricas en expresión y detalle. No obstante, una clasificación útil, sencilla y precisa, es la que expone

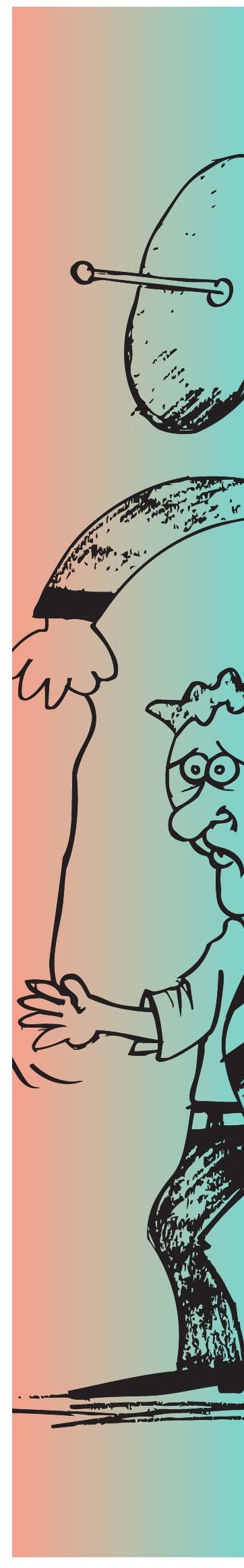




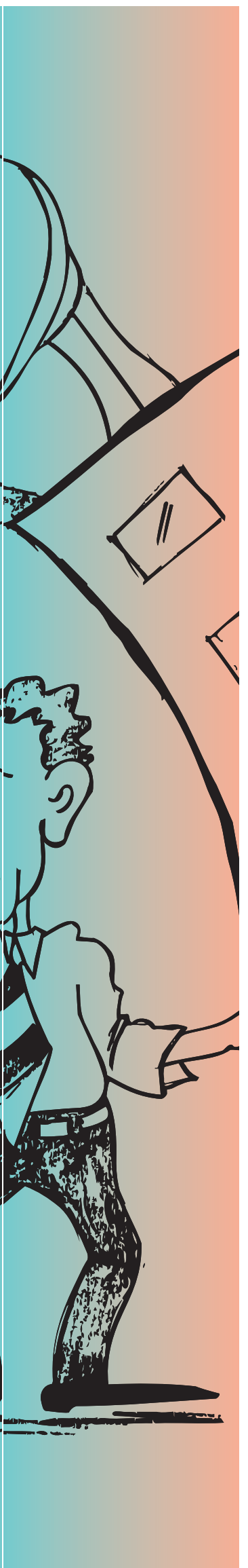

el periodista argentino Daniel Santoro (Santoro, 2004: 22). De acuerdo con este periodista, quien es un especialista en periodismo de investigación, las fuentes de información son de tres tipos: orgánicas, inorgánicas y digitales.

En las orgánicas se agrupa a todos los seres vivos e, inclusive, al germoplasma, lo que incluye a la especie humana. Son inorgánicas los objetos de la naturaleza, una piedra, por ejemplo, y los de la cultura, una casa, un auto, un libro, documentos, fotografías y otros.

Las fuentes de información digitales son todos los respaldos magnetofónicos y soportes contemporáneos que contienen información, como los $\mathrm{CD}$, blueray, flash memory, Internet y redes sociales como Facebook y Twitter.

Así, todo lo que rodea al ser humano puede, en algún momento, convertirse en fuente de información periodística. Para ello, solamente se requiere que juegue en su favor la coyuntura informativa y el interés, espontáneo u orientado, del constructor de significados socioculturales. En este punto, cabe puntualizar que el periodista no es un redactor de sucesos novedosos, tampoco un secretario de la realidad y menos un notario de casos de interés colectivo. El periodista es un constructor de significados socioculturales. O como lo diría el maestro español, Enrique de Aguinaga (De Aguinaga, 2008: 12), es un operador semántico. Su trabajo no confronta la artesanía de las palabras, sino la construcción de significados masivos.

Ponga atención a esto, para que algo sea noticia o novedad deben converger dos factores: coyuntura informativa e interés del constructor de significados socioculturales. Sin esta confluencia no existe novedad y, por ello, es innecesario el uso de fuentes de información.

Sin novedad no existe periodismo. Esto ocurre porque la novedad necesita de las fuentes de información para validar su existencia y sustentar su verosimilitud, o lo que parece verdadero, según explicaba Aristóteles a sus discípulos, cuando se refería a la poética y la retórica. Para este filósofo griego, el poeta, o narrador para el caso de este artículo, no cuenta los hechos como sucedieron, sino como desearía que hubiesen pasado (Aristóteles, 2005: 110). Lo que supone un ejercicio de interpretación y producción de sentido.

El periodismo, visto así, no trabaja sobre la verdad, sino en torno a lo que parece verdadero o eikos. Sobre la verdad es mejor recordar la definición de Nietzsche, quien dice que esta es "un ejército móvil de metáforas, metonimias, antropomorfismos, en pocas palabras, una suma de relaciones humanas que, poética y retóricamente realzadas, fueron traspuestas, adornadas y que, tras largo uso, a un pueblo le parecen fijas, canónicas y obligatorias" (Nietzsche, 1999: 67).

Recuerde usted, el periodismo es verosimilitud, de ahí la importancia de una fuente de información, que sirve para crear argumento y `certeza' de la existencia de la novedad informativa. Una fuente, en ese sentido, no solo es referencia del hecho novedoso, sino significado y 'certeza' sobre los hechos que preocupan a la sociedad. 


\section{La fuente diferencia hecho de opinión}

El relato sociocultural mediático de un hecho novedoso genera opinión masiva, inmediata, mediata y, en ocasiones, a largo plazo, por lo que el uso riguroso de fuentes de información permite distinguir hecho informativo de su opinión.

No es lo mismo novedad que opinión, aunque este sea un tema de permanente discusión y controversia. Por esa razón, Joaquín Estefanía, en el prólogo de la tercera edición del Libro de Estilo del País de España, dice que ese medio, uno de los más importantes de Europa, persigue "la separación tajante entre información, opinión y publicidad" (El País, 2006: 10).

Esta separación, sin embargo, no pasa de ser un enunciado ético, pues una serie de factores al interior de los medios y del ambiente social no permite objetivar la necesaria diferencia entre hecho y opinión. Comentar algo no es igual a relatar informativamente ese algo. La diferencia estriba en que para relatar la información se requiere indagar el hecho novedoso, a más de incluir fuentes de información y datos explicativos contextuales. Lo que no ocurre con el comentario, que tiene lugar a partir de la lectura del relato y no antes.

\section{Sobreviven en el universo Internet}

Una fuente de información reserva privilegio de actualidad y hasta en tiempo real, como entienden este término las generaciones Facebook y Twitter. En los medios de comunicación tradicionales y en la red, el presente se narra periodísticamente, pero también el ayer; por antonomasia, el tiempo ideal del periodismo, $\mathrm{y}$, aunque resulte paradójico, el futuro se relata también en términos periodísticos y en tiempo real por la 'magia' de la tecnología. Hoy, en el caso humano, una fuente de información puede inclusive remediar una opinión imprecisa o remplazarla con otra si ya no está de acuerdo con la primera.

En las redes sociales, como puede deducirse, las fuentes de información son válidas. De hecho, el Universo Internet cifra su existencia en estas, pues en el ciberespacio ocurre un proceso poco analizado y comprendido de desmediatización y remediatización de los medios tradicionales, como prensa escrita, radio y televisión.

La irrupción de las llamadas Tecnologías de la Información y Comunicación (Tic's) provocó desde hace 20 años, aproximadamente, una ruptura en el paradigma periodístico y, en este sentido, de las fuentes de información.

Internet y, dentro de este, las redes sociales, resignifican el sentido de una fuente de información, pero no la remplazan ni la desacreditan. El cambio está en el volumen de fuentes de información, el tiempo real y la interacción de la fuente de información con los consumidores de significados masivos. Puede notarse, sin existir aún una medición disponible, que en Internet existe más concentración mediática y de producción de significados socioculturales de valor periodístico, que hace 
diez años. La población mundial creció, es cierto, pero también más personas acceden hoy al ciberespacio y ejercitan, de una u otra forma, su derecho humano a informarse, pero también a expresar sus puntos de vista y opiniones sobre un hecho. Son fuentes de información espontánea.

Este cambio en las prácticas de consumo de información mediáticas y periodísticas es analizado por expertos en el tema. Por ejemplo, Silvio Waisbord, periodista argentino, radicado en Estados Unidos, dice, sobre el acceso de las personas a medios web, que "al consumir información maximizamos el tiempo, se consume más información ahora que antes. Pero eso no significa que estemos abiertos a consumir cualquier tipo de información. En sus hábitos de utilización de la información, la gente es muy conservadora: visita los mismos sitios siempre -como Google o Yahoo, o The New York Times, Clarín o Página/12-, como puntos de entrada hacia el gran universo "http://www.señales.com.net//"www.señales.com. net//. Acceso, 4 de enero de 2013).

\section{Fuentes de información revelan la opinión del periodista}

Por lo explicado, las fuentes de información forman parte de la práctica periodística, rigurosa y seria, por lo que su utilidad es incuestionable. Una fuente no reemplaza al hecho, sino que lo describe y se constituye en su argumento y 'certeza'. El periodista relata un hecho novedoso, a través de sus fuentes de información. Esto exige rigor metodológico y honestidad intelectual. Se deben utilizar fuentes de información, de manera precisa, con datos completos y corroborados, aún en el caso de ser testigo de excepción, como argumento del hecho informativo, evidencia de la verosimilitud del suceso de relato periodístico y testimonio histórico de los protagonistas del caso novedoso.

Es a través de estas fuentes de información que el periodista valora la realidad y construye una opinión sobre esta. La fuente ya tiene o traduce una versión precisa de la realidad, por lo que el privilegio de una, en lugar de otra, conlleva un ejercicio político de valoración y selección del imago mundo o representación de la realidad, como lo sugiere el maestro Enrique De Aguinaga (De Aguinaga, 2008: 15). La fuente, entonces, revela la opinión e ideología del periodista.

\section{Esos errores... ¿ ¿son errores?}

Utilizar fuentes de información es cosa seria. Por esta razón, reemplazarlas sin sentido, o con un propósito desconocido para el público, por adverbios de cantidad, es una forma cuasi delictiva de ejercer la profesión periodística.

No se puede, y no se debe, reemplazar una fuente de información por adverbios como muy, mucho, poco, bastante, demasiado, menos, más, algo, casi, sólo, solamente, tan, tanto, nada, todo y otros. Esto, porque nada puede remplazar la vali- 
dez, precisión y alcance testimonial de una fuente de información.

El adverbio, en el contexto del periodismo, revela imprecisión en el dato y en el personaje de la novedad, pero también puede encubrir la inexistencia de una fuente que relate los hechos, según su propia versión.

Imagine esta frase periodística: muchos testigos dijeron que el accidente de tránsito ocurrió porque el conductor iba en estado de ebriedad. Pregunta inevitable, ¿quiénes son esos muchos?, ¿̇por qué no se identifica a esos muchos? ¿Existen de verdad? ¿Por qué se los oculta? Igual ocurre con el uso de otros adverbios, como varios y algunos, de uso frecuente en el periodismo ecuatoriano.

Como podrá connotarse, al pensar las fuentes de información periodística, la reserva de estas entra en crisis. Se abre un momento de ruptura al interior del periodismo, que revela la necesidad de identificar todas las fuentes y buscar los mecanismos posibles para que estas se objetiven y visibilicen no solamente en la información, sino en la sociedad, con todas sus intencionalidades y 'certezas'.

\section{¿Quiénes son fuente de infor- mación?}

La respuesta parecería obvia, pero no lo es. No son, necesariamente, fuentes de información periodística quienes protagonizan un hecho novedoso o quienes aportan positivamente a la sociedad.

Son fuentes quienes pueden visibilizarse en el escenario informativo sociocultural. Este protagonismo ocurre por la convergencia de estos factores:
- Trascendencia del hecho novedoso

- Importancia del sujeto del hecho

- Impacto del relato en la sociedad

- Agenda política mediática

Queda claro, entonces, que para ser fuente de información no basta solamente con ser protagonista de un suceso novedoso, sino que se requiere ser importante como sujeto del hecho novedoso, como se notará líneas abajo.

Esto, de alguna manera, es superado en el periodismo de crónica roja, que convierte en protagonistas a sujetos sin ninguna importancia para

La crónica roja, irrumpe en el periodismo como la sociedad. Como si fuese una agenda social de los extramuros, se incluyen esos nombres y apellidos altisonantes para el poder, ahí están quienes ganan fugaz notoriedad por ser supuestos criminales y asesinos, las trabajadoras sexuales, las amas de casa y los trabajadores de baja jerarquía.

etras fuentes de información La crónica roja irrumpe en el periodismo como un lenguaje abyecto y genera una nueva ruptura, por la inclusión de esas otras fuentes de información.

\section{Fuentes de información en el Ecuador}

De acuerdo con el informe preliminar de una investigación, desarrollada bajo la guía de quien suscribe este artículo, en la cátedra de Periodismo I, en la Facultad de Comunicación Social de la Universidad Central del Ecuador, durante el semestre 2012-2012, el imaginario mediático se construye con fuentes de información que proyectan la palabra de figuras recurrentes. La investigación partió de una pregunta sencilla: ¿quiénes son fuentes de infor- 
mación en el país? La indagación abarcó a tres medios en cada uno de estos grupos: medios impresos, medios radiales, medios televisivos y medios on line, durante el segundo semestre de 2012.

Estos son tres de los resultados obtenidos, de forma preliminar, y que esperan aún ser completados y validados.

\begin{tabular}{|l|c|}
\hline \multicolumn{1}{|c|}{ Principal fuente de información } & $\%$ \\
\hline Político & 37 \\
\hline Futbolista & 22 \\
\hline Famoso (cantante, periodista, reina de belleza y otros) & 20 \\
\hline Protagonistas de hechos delictivos & 17 \\
\hline Promotores sociales & 1 \\
\hline Inventores, científicos & 1 \\
\hline Otros & 2 \\
\hline TOTAL & 100 \\
\hline
\end{tabular}

La fuente "político" fue recurrente en el imaginario mediático, para el período de análisis, por la coyuntura informativa que, entonces, agrupaba temas como las denuncias contra el régimen, por el título profesional de dos de sus colaboradores: Pedro Delgado (exgerente del Banco Central, autor confeso de un título falso) y Jorge Glass (candidato vicepresidencial, por posible plagio de su tesis), así como por la inminencia de la campaña política presidencial que arrancó el cuatro de enero de 2013.

Esto no significa, sin embargo, minimizar el protagonismo que asignan los medios ecuatorianos a las fuentes políticas, sobre todo después de la ruptura provocada por el régimen de Alianza País en contra de la llamada partidocracia.

Otras fuentes claves en el periodismo ecuatoriano, como futbolistas y famosos, forman parte de la representación colectiva del éxito, por lo que su presencia mediática, como fuente, resulta imprescindible a la hora de construir novedad.

\begin{tabular}{|l|c|}
\hline \multicolumn{1}{|c|}{ Pertenencia geracional de la fuente de información } & $\%$ \\
\hline Menor - niño & 3 \\
\hline Menor - adolescente & 15 \\
\hline Joven & 25 \\
\hline Adulto & 44 \\
\hline Adulto Mayor & 11 \\
\hline Otros & 2 \\
\hline TOTAL & 100 \\
\hline
\end{tabular}


El adulto es principal fuente de información mediática. Le siguen los jóvenes, pero al ser protagonistas de movilizaciones, escándalos y otros, durante el periodo de análisis, como su liderazgo en las protestas contra la Feria de Taurina en Quito y en la liberación de los jóvenes acusados de terrorismo por el Gobierno. La presencia positiva del joven, como fuente de información, no es frecuente en los medios de comunicación ecuatorianos.

De otra parte, la presencia del menor de edad es escasa y claramente positiva, como en el caso de la promoción de sus logros académicos en la escuela. Ya no es fuente de información negativa, por la normativa jurídica existente, que prohíbe la publicidad de menores como sujetos de cualquier información que pueda violentar sus derechos.

La presencia masculina, como fuente de información, es determinante en los medios de comunicación ecuatorianos, más si se piensa esto junto con la variable política, cuyo eje gira en torno a líderes de origen masculino. Sin embargo, la presencia femenina es significativa, no porque sean ya una fuente de información cotidiana a nivel mediáti- co, sino por la coyuntura política del gobierno de Rafael Correa, que tiene entre sus figuras, en calidad de ministras y asambleístas, a un importante número de mujeres.

La identidad GLBTI, en contraste, se representa de forma aún sórdida en los medios de comunicación analizados. La presencia de gays, lesbianas, transgéneros e intersex, como fuente de información mediática, fue por protagonizar escándalos, muertes y por denuncias en contra del Estado al percibir amenazados sus derechos.

Además, esta presencia como fuente aumentó durante el periodo analizado, como respuesta a las declaraciones homofóbicas que hizo el candidato presidencial del Partido Roldosista Ecuatoriano, el pastor Nelson Zabala, quien calificó a los GLBTI de ‘inmorales' y 'anormales'.

Para concluir, solo basta regresar sobre el título de este artículo: las fuentes de información retratan la realidad de un país.

Quito, 12 de enero de 2013.

\begin{tabular}{|l|c|}
\multicolumn{1}{|c|}{ Género de la fuente de información } & $\%$ \\
\hline Masculino - hombre & 51 \\
\hline Femenino - mujer & 37 \\
\hline GLBTI & 12 \\
\hline TOTAL & 100 \\
\hline
\end{tabular}




\section{Bibliografía y consultas on line}

- $\quad$ ARISTÓTELES. Poética. Madrid, Gredos, 2005.

- $\quad$ ARISTÓTELES. Metafísica. Madrid, Gredos, 2007.

- BENÍTEZ, José Antonio †La noticia integral. La Habana. Editorial Pablo de la Torriente. 2001.

- BENÍTEZ, José Antonio. Técnica periodística. Imprenta Universitaria de Oriente. La Habana, Cuba. 1971.

- CHALMERS, ALAIN: “¿Qué es esa cosa llamada ciencia?”, Siglo XXI, HYPERLINK "http://www.monografias.com/trabajos901/historia-madrid/historiamadrid.shtml"Madrid, "http://www.monografias.com/trabajos6/hies/hies. shtml" España, 1998.

- DE AGUINAGA, Enrique, Hacia un nuevo Concepto de Redacción Periodística, Revista Contextos No.29, Universidad del Valle de Cali, Colombia, 2003.

- $\quad$ El País, Libro de Estilo, Tercera edición, Madrid, España, 2006.

- KUHN, THOMAS: "La estructura de las revoluciones científicas", FCE, "http://www.monografias.com/trabajos/histomex/histomex.shtml”México, 1971.

- NIETZSCHE, Friedrich (2004). Sobre verdad y mentira en sentido extramoral. Bogotá, Universidad Nacional de Colombia, 1999.

- SANTORO, Daniel, Periodismo de Investigación, Fundación para un Nuevo Periodismo Iberoamericano, Cartagena de Indias, Colombia, 2003Internet

- Saint-Paul, 2013, Fuentes de información y poder, http/www.estrategia21.net. Acceso, 8 de enero de 2013

- WAISBORD, Silvio, Periodismo en la Era Digital, http://"http://www.señales.com.net//"www.señales.com.net//. Acceso, 4 de enero de 2013. 